\title{
EXPERIMENTAL STUDY THE PERFORMANCE OF RAM WATER PUMP
}

\author{
Hussein T. Dhaiban \\ Department of Refrigeration and Air-Conditioning Tech. Eng. \\ Dijlah University College \\ Al-Massafi str., Baghdad, Iraq, 00964 \\ hussein.talal@duc.edu.iq
}

\begin{abstract}
Ram water pump is one types of renewable energy that work without any source when used to provide energy from water power for changing the potential energy to kinetic energy to use for agriculture fields. The device must find near the rivers to useful from water to work and the waste water return to the river again. The performance of the ram pump is studied experimentally. The device is simple contain from fittings, tank, pipes, pressure vessel and valves. Three inlet diameter (1/2, 3/4 and 1 in) at inlet pipe is used, and three level of tank water supply $(1.9,1.8$ and $1.65 \mathrm{~m})$ is studied. Also, three ways is used to change the pressure in the vessel. The aim of this paper is studying the effect of change the inlet diameter and water level at the height and flow rate at the exit. Also, study the efficiency of the test device.

The results show inversely relationship between the head and flow rate at the exit and the pressure in the vessel is not effected to the head and exit flow rate. Additionally, the maximum efficiency is $29 \%$ at $1.9 \mathrm{~m}$ tank height and 0.5 in diameter.
\end{abstract}

Keywords: fluid mechanics, hydraulic, pump, ram, performance, efficiency.

\section{Introduction}

A pump is a device that used to move and transfer the fluids from point to another by mechanical action. Three major groups of pumps that classify according to the action that used to transfer the fluid: gravity, direct lift and displacement pumps. The mechanism of pumps that operate at typically reciprocating or rotary, and generate energy to perform mechanical work by moving the fluid. Many uses of pumps that operated at the energy sources, including manual operation, electricity, engines, or wind power, come in many sizes, from microscopic for use in medical applications to large industrial pumps [1].

Many studies in this area to study the ram water pump. The design and construction of ram water pump by four ways to left the water from $2 \mathrm{~m}$ when the results showed the maximum rate at exit was $2.7 \mathrm{lit} / \mathrm{min}$ and efficiency $57.3 \%$ [2]. And, the design and performance evaluation of a downdraft hydraulic ram pump when the results showed at 2-in diameter the minimum inflow $2.4 \mathrm{gal} / \mathrm{min}$ and discharge $0.2 \mathrm{gal} / \mathrm{min}$. Also, at 3 -in the minimum in flow $20.4 \mathrm{gal} / \mathrm{min}$ to give the discharge $1.53 \mathrm{gal} / \mathrm{min}$. All the conditions at $1 \mathrm{ft}$ vertical fall $8 \mathrm{ft}$ vertical lift [3]. Also, scientists [4] studied the experimentally and analytically the performance testing of hydraulic ram pump. They studied the effect of delivery head, supply head and weight on the waste valve. Results showed the maximum head was $4 \mathrm{~m}$ when the supply head $0.5 \mathrm{~m}$. The development of the design of hydraulic ram water is found solution in India villages [5]. The effect of diameter and length of drive pipe, flow rate at exit, pressure at waste valve and the power of hydro ram was studied [6].

In this experimental research, study the effect of change the inlet diameter and inlet water level to the head and amount of flow rate at the exit. Also, study the efficiency of the test device.

\section{Hydraulic ram pumps}

A hydraulic ram defines as a water pump that powered by hydropower and not need any source of energy to work. Therefore, it's one types of renewable energy. From this reason, the ram pump is used for agriculture.

It takes in water at relatively low pressure and high flow-rate and outputs water at a higher hydraulic-head and lower flow-rate. The device uses the water hammer effect to develop pressure that lifts a portion of the input water that powers the pump to a point higher than where the water started, as shown in Fig. 1. 
The hydraulic ram is sometimes used in remote areas, where there is both a source of lowhead hydropower, and a need for pumping water to a destination higher in elevation than the source. In this situation, the ram is often useful, since it requires no outside source of power other than the kinetic energy of flowing water [7].

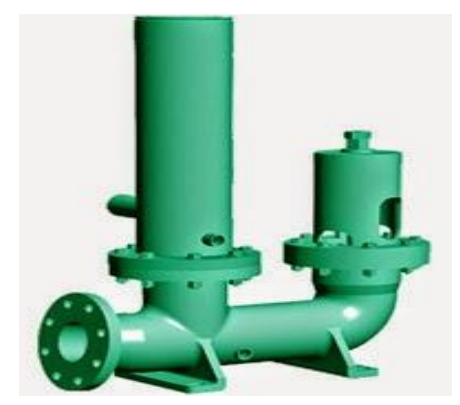

Fig. 1. Hydraulic Ram Pump

Hydraulic ram pump depends mainly on the flow of water as the source of an essential energy. All hydro water pump are found in the ongoing precisely rivers. The pump operates similarly to the work of the electrical transformer where convert the energy flow of water entering the high flow and low pressure to the flow of energy with low-flow and high pressure with some losses. This means they do not need an external source for its operation relies self-employment of the same water flow principle. High pressure is created by the phenomenon of roads.

Roads phenomenon in the process fluid is the sudden rise in pressure of the fluid flowing at high speed and the freedom to suddenly hit the barrier in front of him.

\section{Principle of operation}

Roads phenomenon that shown in Fig. 2 occurs at the pump when the output water remnants gate valve closes suddenly as that in the normal state is assumed that water flowing from the supply tank passing through the drive pipe (No. 1) and carried out of the water to point (No. 2), but its flow speed drive valve output suddenly closing creates pressure opposite to the flow of water, which in turn distributed over around the inner wall of the container of water in the pump, including the check valve (No. 5) to open the turn and rushes of water up in each of the tube supply and pressure tank. When the water stops for rush because of the blockage, the water in the reservoir and tube supply tries to back down while the check valve with closure automatically (this is its working unidirectional valve). The output valve (No. 4) opens again to the lack of water and thus pay process will continue again while the running water to re-close the output valve [8].

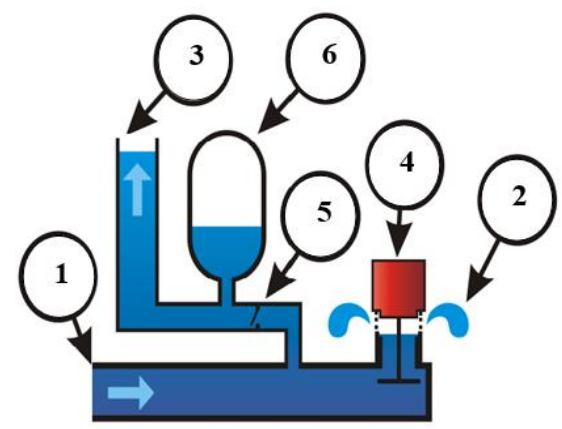

Fig. 2. Hydraulic ram pump

\section{The device components}

All the components of the test rig are design based on the manual of hydraulic ram pump [9] that tabulated and description in Fig. 3 and Table 1. 


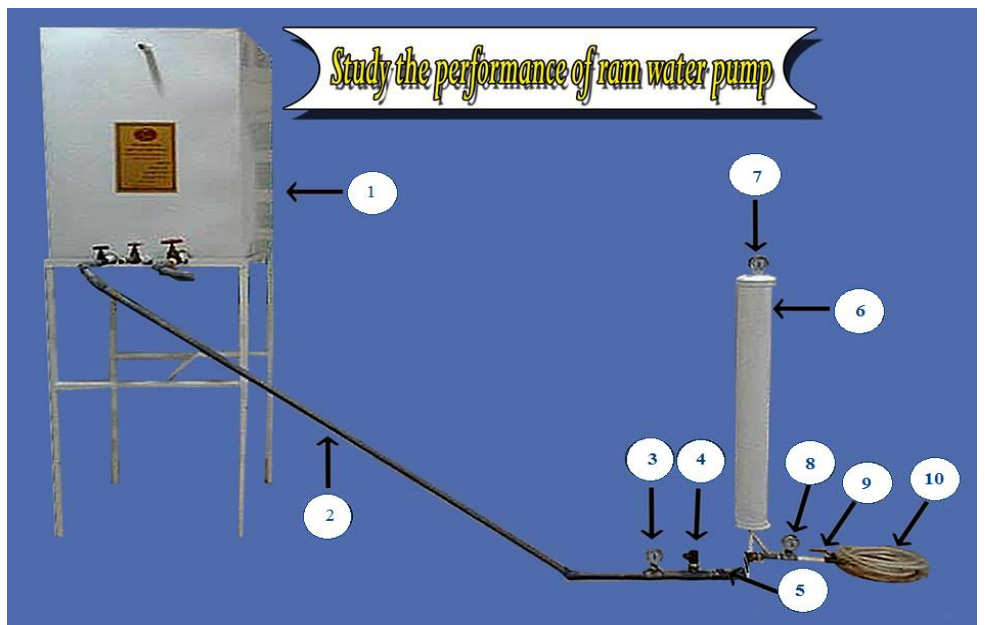

Fig. 3. Hydraulic ram pump of the test rig: 1 - Tank; 2 - Drive Pipe; 3 - Pressure gauge I; 4 - Check valve I; 5 - Check valve II; 6 - Pressure vessel; 7 - Pressure gauge II; 8 - Pressure gauge III; 9 - Gate valve; 10 - Delivery Pipe

Table 1

Minor and major device components

\begin{tabular}{cccc}
\hline Part Name & Metal & Dimension & Function \\
\hline Tank (Water Source) & Galvanized Iron & $(0.5 \times 0.5 \times 1.25) \mathrm{m}$ & Water storage \\
Drive Pipe & PVC & $(1 / 2,3 / 4,1) \mathrm{in}$ & Water transfer from tank \\
Delivery Pipe & Flexible Rubber & $1 / 2$ in & Water transfer to exit \\
Storage Tank & Rubber & $(0.25 \times 0.25 \times 0.5) \mathrm{m}$ & Water Storage \\
Pressure Vessel & PVC & $\mathrm{D}=4$ in and $\mathrm{L}=1 \mathrm{~m}$ & Estimate the flow rate at the exit \\
Beaker & Glass & 1 litter & Waste valve \\
Check Valve & Brass & $3 / 4$ in & to control the flow rate \\
Gate Valve & Brass & - & to measure the pressure \\
Pressure Gauge & Brass & - & pipe fitting \\
Tee & Brass & $3 / 4$ in & \\
Elbow 90 & PVC & $3 / 4$ in & $3 / 4$ in \\
Tee & PVC & PVC & $1 / 2$ in $-3 / 4$ in
\end{tabular}

\section{Theoretical equations}

The efficiency of the test device that estimated by using the equation below [10]:

$$
\eta=\mathrm{q} \cdot \mathrm{h} / \mathrm{Q} \cdot \mathrm{H}
$$

where $\eta=$ pump efficiency; $\mathrm{H}$ - tank height at inlet (m); $\mathrm{h}$ - tank height at exit (m); Q - volume flow rate at inlet (LPM); q - volume flow rate at exit (LPM).

The volume flow rate $(\mathrm{Q})$ at the exit can be calculated by using flow meter as:

$$
\mathrm{Q}=\mathrm{V} \cdot \mathrm{A},
$$

where $\mathrm{V}$ - inlet velocity, $\mathrm{m} / \mathrm{s} ; \mathrm{A}$ - cross section area, $\mathrm{m}^{2}$. 
But, the (q) can be measured by using the simple ways of determine the flow rate by using a) cylinder beaker known volume b) timer as

$$
\mathrm{q}=\mathrm{V} / \mathrm{T}
$$

where V - volume, $\mathrm{m}^{3} ; \mathrm{T}$ - time, $\mathrm{s}$.

\section{Device specification}

All the test specification of the model and condition of the calculation are shown in Table 2.

Table 2

Device specification

\begin{tabular}{ccc}
\hline Specification & Value & Unit \\
\hline flow rate at inlet & 7 & LPM \\
slop of inlet pipes & 30 & degree \\
length of inlet pipe & 1.5 when using 0.5 in diameter & m \\
& 1.9 when using 0.75 in diameter & in \\
inlet diameter & 2.1 when using 1 in diameter & in \\
outlet diameter & $0.5-0.75-1$ & m
\end{tabular}

\section{Results and discussion}

In this study, the head and the flow rate was calculated in three inlet water level (1.9, 1.8 and $1.65) \mathrm{m}$ at three inlet pipe diameter $(0.5,0.75$ and $1 \mathrm{in})$ at constant inlet flow rate 7 LMP.

The results show the head and flow rate at the exit not effected by changing the pressure value in pressure vessel, although changing it by three ways:

a) using filter cartridge;

b) balloon from rubber;

c) pressuring it by air from hole at the outside surface.

The Fig. 4-6 discusses the relationship between the head (m) at exit pump at the X-axis and the volume flow rate (LPM) at the Y-axis at height of inlet water supply level at (1.9, 1.8 and 1.65) $\mathrm{m}$. Results show when increased the head, the flow rate was decreased that mean inversely relationship. Also at the diameter ( $0.5 \mathrm{in})$ is better from other diameter by the head and flow rate. Additionally, the maximum flow rate shows in $(0.5 \mathrm{in})$ diameter at $1.9 \mathrm{~m}$ water supply level.

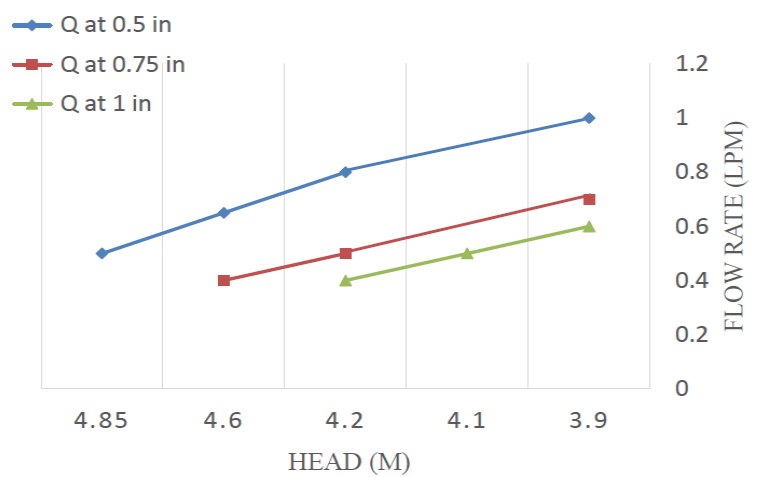

Fig. 4. Head against flow rate at different diameters at $1.9 \mathrm{~m}$ supply water level 


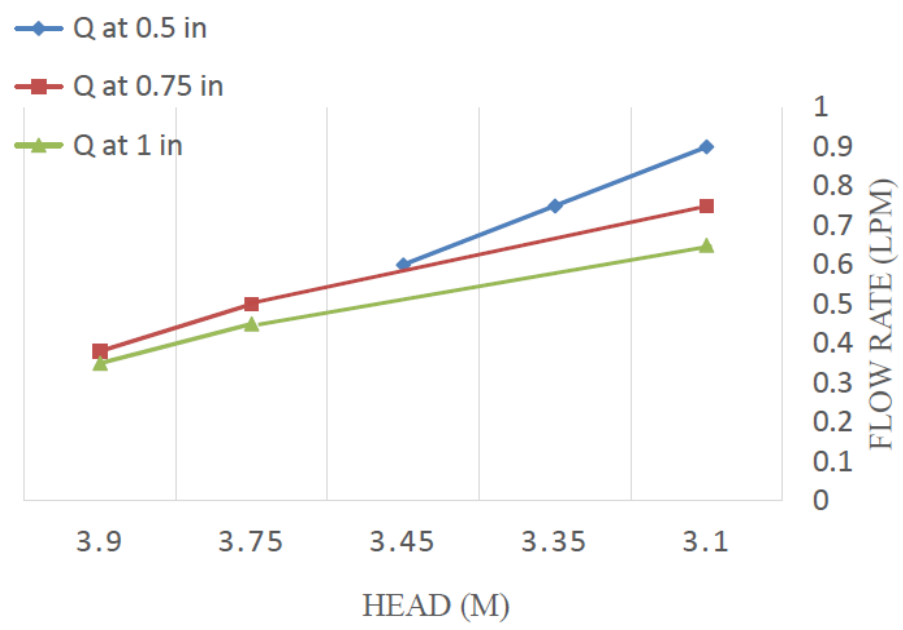

Fig. 5. Head against flow rate at different diameters at $1.8 \mathrm{~m}$ supply water level

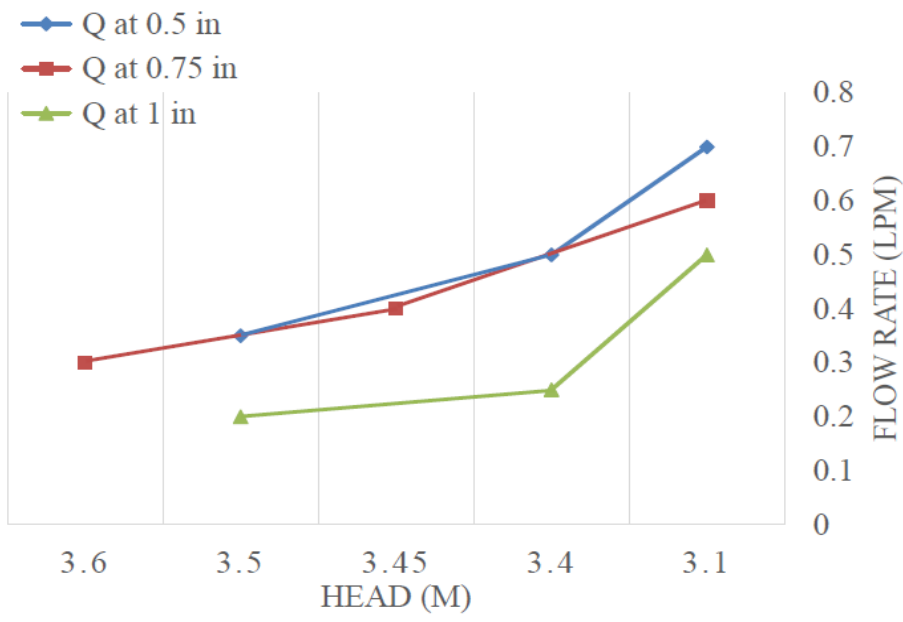

Fig. 6. Head against flow rate at different diameters at $1.65 \mathrm{~m}$ supply water level

The bar chart in Fig. 7 discusses the relationship between inlet pipe diameter (in) at the $\mathrm{X}$-axis and the efficiency at the Y-axis at different tank heights. Results show inversely relationships between the pipe diameter and the efficiency. Also the efficiency is increase by increasing the tank height. And it is closely value at high diameter $(1 \mathrm{in})$. Additionally, the maximum efficiency reaches to $29 \%$ at the $(1.9 \mathrm{~m})$ tank height and $(0.5 \mathrm{in})$ inlet diameter.

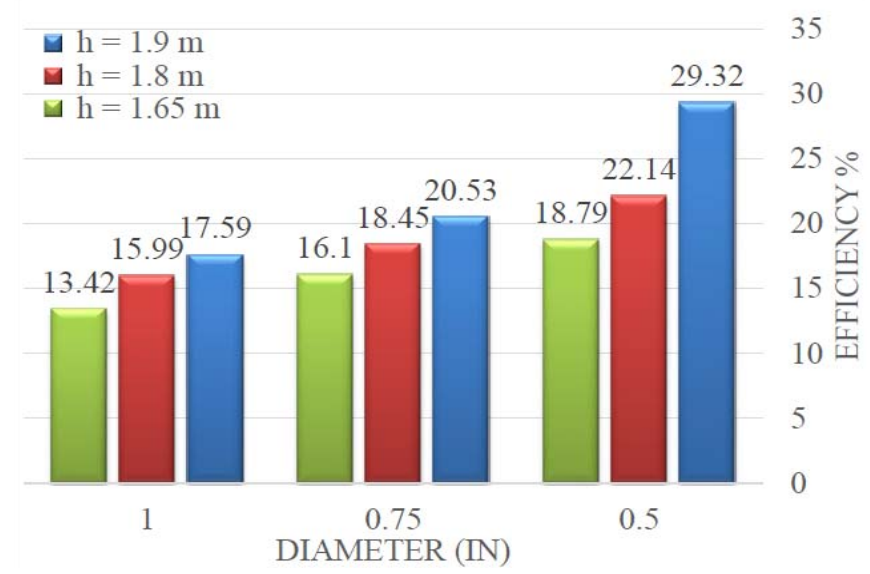

Fig. 7. Efficiency against inlet diameter at different tank supply height 
For comparison the efficiency results with other research [11] at the same inlet tank supply height $(1.8 \mathrm{~m})$ with different inlet diameters, this experiment at $(0.75 \mathrm{in})$ and the research experiment at (1.25 in). The comparison results shows efficiency enhancement at $17 \%$ when the research efficiency $15 \%$ and while this experiment $-18.45 \%$.

The main aim of this article is proposal for built the test rig used to the measure various studies occurring while working in water ram based on the construction recommendations and it will be sample replaced in parts to be maintenance.

Finally, the main problems remain not solved is to be the large amount of waste water and the noise of work. It can be suggest to solve the problem by using techniques in system design to collect and return the waste water to the tank.

\section{Conclusion}

Results show inversely relationship between the head and the amount of flow rate at the outlet. Also, the head and flow rate at the exit is not effected by changing the pressure inside the vessel. Additionally, the maximum efficiency that depended at potential energy of water reach to (29\%) at the supply tank height $1.9 \mathrm{~m}$ and inlet diameter $(0.5 \mathrm{in})$. Finally, the maximum enhancement reaches to $17 \%$ when compared with research [11] at same supply heat at $1.8 \mathrm{~m}$.

\section{References}

[1] Improving Pumping System Performance: A Sourcebook for Industry (2006). United States. Department of Energy, 122.

[2] Mohammad, S. N. (2007). Design and Construction of Hydraulic Ram Pump. Leonardo Electronic Journal of Practices and Technologies, 59-70.

[3] Dumaoal, A. F., Urbano, F. A., Pareja, B. P. Design and Performance Evaluation of a Local Downdraft Hydraulic Ram Pump. Available at: http://ilarrdec.mmsu.edu.ph/documents/Ram_Pump_ Design_Paper.pdf

[4] Mbiu, R. N., Maranga, S. M., Mwai, M. (2015). Performance Testing of Hydraulic Ram Pump. Proceedings of the Sustainable Research and Innovation (SRI) Conference, 6-8.

[5] Atharva, P., Aniruddha, D., Santosh, K., Sagar, M., Mamta, P. (2016). Design of Hydraulic Ram Pump. International Journal for Innovative Research in Science \& Technology, 2 (10), 290-293.

[6] Sheikh, S., Handa, C., Ninawe, A. (2013). Design Methodology for Hydraulic Ram Pump. IJMERR, 2 (4), 170-175. Available at: http://www.ijmerr.com/v2n4/ijmerr_v2n4_20.pdf

[7] John, C. (2003). Home Built Hydraulic Ram Pumps. NW Independent Power Resources, 84. Available at: http://www.inthefieldministries.org/jscalhou/Home \%20Built \%20Hydraulic \%20Ram \%20 Pumps.pdf

[8] Verspuy, C., Tijsseling, A. S. (1993). Hydraulic ram analysis. Journal of Hydraulic Research, 31 (2), 267-278. doi: https://doi.org/10.1080/00221689309498849

[9] Watt, S. B. (1975). Prelims - A Manual on the Hydraulic Ram for Pumping Water. Intermediate technology publication. doi: https://doi.org/10.3362/9781780441603.000

[10] Inthachot, M., Saehaeng, S., Max, J. F. J., Müller, J., Spreer, W. (2015). Hydraulic Ram Pumps for Irrigation in Northern Thailand. Agriculture and Agricultural Science Procedia, 5, 107-114. doi: https:// doi.org/10.1016/j.aaspro.2015.08.015

[11] Hussin, N. S. M., Gamil, S. A., Amin, N. A. M., Safar, M. J. A., Majid, M. S. A., Kazim, M. N. F. M., Nasir, N. F. M. (2017). Design and analysis of hydraulic ram water pumping system. Journal of Physics: Conference Series, 908, 012052. doi: https://doi.org/10.1088/1742-6596/908/1/012052 